\title{
Maternal Deprivation Increases Vulnerability to Morphine Dependence and Disturbs the Enkephalinergic System in Adulthood
}

\author{
Vincent Vazquez, ${ }^{1}$ Jacqueline Penit-Soria, ${ }^{2}$ Claudette Durand, ${ }^{2}$ Marie Jo Besson, ${ }^{2}$ Bruno Giros, ${ }^{1}$ and Valérie Daugé ${ }^{1}$ \\ ${ }^{1}$ Institut National de la Santé et de la Recherche Médicale, U513, Laboratoire de Neurobiologie et Psychiatrie, Université Paris XII, Faculté de Médecine, \\ 94010 Créteil, France, and ${ }^{2}$ Centre National de la Recherche Scientifique, Unité Mixte de Recherche 7624, Laboratoire de Neurochimie Anatomie Institut \\ des Neurosciences, Université ParisVI, 75005 Paris, France
}

\begin{abstract}
Maternal deprivation can trigger long-lasting molecular and cellular modifications in brain functions and might facilitate the appearance of pathogenic behaviors. This study focuses on the vulnerability to develop morphine dependence in adult rats that were separated from their mother and littermates for $3 \mathrm{~h}$ per day for $14 \mathrm{~d}$ after birth and examines the adaptive changes in the enkephalinergic pathways. Place-preference conditioning was observed with $2 \mathrm{mg} / \mathrm{kg}$ morphine in deprived rats, whereas $5 \mathrm{mg} / \mathrm{kg}$ morphine was necessary to induce conditioning in nondeprived animals. A prolonged morphine conditioning was shown in deprived rats. A strong increase in oral morphine self-administration behavior and preference was observed in deprived rats. Only a very slight increase in preference for sucrose solution, a more ethological reinforcer known to interact with the opioid system, was shown in deprived rats. These results indicate that this postnatal environment change leads to a hypersensitivity to the reinforcing properties of morphine and to the development of morphine dependence. A significant decrease in preproenkephalin mRNA expression was observed in the nucleus accumbens and the caudate-putamen nucleus of deprived rats. The basal extracellular levels of the Met-enkephalin-like immunoreactivity in the nucleus accumbens were significantly lower in deprived rats when compared with nondeprived animals, whereas no change in $\mu$-opioid receptor binding occurred. These results strongly support that maternal deprivation leads to a basal hypoactivity of the enkephalinergic system and hypersensitivity to morphine effects.
\end{abstract}

Together, our results suggest that maternal deprivation in pups likely represents a risk factor for morphine dependence in adult rats.

Key words: maternal deprivation; oral morphine and sucrose self-administration; place-preference paradigm; preproenkephalin mRNA; extracellular Met-enkephalin; $\mu$-opioid receptors

\section{Introduction}

The concept of interindividual vulnerability applied to psychiatric disorders implies both genetic and environmental factors. Among the latter, adverse postnatal environments were shown to increase the risk to develop depression, anxiety, and substance abuse (Holmes and Robins, 1987; Canetti et al., 1997). To understand long-term changes that may take place in humans, animal models of postnatal environment changes have been established. Several studies suggest that long maternal separation (MS) leads to anhedonia in the rat that resembles core aspects of human depression (for review, see Matthews and Robbins, 2003). Other

Received Nov. 24, 2004; revised March 9, 2005; accepted March 15, 2005.

This work was initiated in the Département de Pharmacochimie Moléculaire et Structurale, Institut National de la Santé et de la Recherche Médicale, U266 (Paris, France); the Centre National de la Recherche Scientifique, Formation de Recherche Evolutive 2463 (Paris, France); and the Université Paris V (Paris, France). We thank Stéphane Lamouraux, Jean Luc Marie, and Corinne Canestrelli for technical assistance and Jacqueline Gilchrist for stylistic revision of this manuscript. We gratefully acknowledge Prof. B. P. Roques for early support in the course of this study.

Correspondence should be addressed to Dr. Valérie Daugé, Institut National de la Santé et de la Recherche Médicale, U513, Laboratoire de Neurobiologie et Psychiatrie, Université Paris XII, Faculté de Médecine, 8 rue du Général Sarrail, 94010 Créteil, France. E-mail: dauge@im3.inserm.fr.

D0I:10.1523/JNEUROSCI.4807-04.2005

Copyright $\odot 2005$ Society for Neuroscience $\quad$ 0270-6474/05/254453-10\$15.00/0 studies raise the hypothesis of a vulnerability to stress-induced illness (for review, see Anisman et al., 1998; Francis et al., 1999). Some data show cocaine or alcohol dependence (Kosten et al., 2000; Huot et al., 2001; Ploj et al., 2003a) as well as anxiety and depression-like syndromes occurring after MS with potentially common neurocircuitry (Huot et al., 2001) (but see Pryce and Feldon, 2003). Enduring changes in the hypothalamic-pituitaryadrenal, monoaminergic, and GABAergic systems in MS were described previously (Meaney et al., 1989, 2002; de Kloet et al., 1996; Ladd et al., 1996; Hall et al., 1999; Caldji et al., 2000; Vazquez et al., 2002). However, there is little data available about the functional state of opioidergic systems.

The opioid peptides, in particular enkephalins, are implicated in pain perception, in response to stress, and in reinforcement (for review, see Vaccarino et al., 1999). There is also evidence that endogenous opioids mediate mother-infant affiliation in various species (Harris and Newman, 1988; Carden and Hofer, 1990). Recent data reveal brain opioid level changes in MS rats (Ploj et al., 2003a,b) as well as changes in morphine-induced tolerance, physical dependence, and locomotor sensitization (Kalinichev et al., 2001, 2002).

This study was performed to examine the long-term effects of 
maternal deprivation (MD) on the enkephalinergic system and on morphine dependence. Deprivation of the mother and littermates ( $3 \mathrm{~h}$ per day from the ages of $1-14 \mathrm{~d}$ ) seems to constitute a more severe postnatal manipulation than MS (separation of the intact litter from the dam) (McCormick et al., 1998). However, it is unclear whether the marked deprivation effects are mediated by human handling, prolonged isolation, altered maternal behavior, or some combination thereof (for review, see Pryce and Feldon, 2003).

Chronic oral morphine self-administration and morphine place-preference conditioning were examined in adult nondeprived (ND) and deprived (D) rats. The measurement of preproenkephalin (PPE) mRNAs and of the extracellular Metenkephalin-like immunoreactivity (Met-LI) levels was performed in the striatum of ND and D rats, especially in the nucleus accumbens (N.Acc.), which is an important region involved in reinforcing processes (for review, see Wise, 1989; Koob, 1992). $\mu$-Opioid receptors were quantified in the striatum and mesencephalon of ND and D rats. The $\mu$-opioid receptor has been shown to be predominantly responsible for the production of euphoria and reward by morphine (for review, see Tzschentke, 1998) and to be physiologically bound by the enkephalins (Reisine and Pasternak, 1996). Another reinforcing compound, sucrose, is known to interact with the opioidergic system was also studied in oral self-administration behavior.

\section{Materials and Methods}

Subjects. Seven series of 20 pregnant Long-Evans rats (Janvier, Le Genest St. Isle, France) on day 14 of gestation were used. The dams gave birth $\sim 1$ week after inclusion and within $12 \mathrm{~h}$ of each other. Litters were housed in clear plastic cages in a well ventilated, temperature-controlled $\left(24 \pm 1^{\circ} \mathrm{C}\right)$ and humidity-controlled $(50 \pm 5 \%)$ environment on a $12 \mathrm{~h}$ light/dark cycle (lights on from 8:00 A.M. to 8:00 P.M.). Dams received rat chow and water ad libitum, and the cages and all of the shavings were changed only once per week to avoid excessive handling.

The experimental procedure and care of the animals were in accordance with local committee guidelines and the European Communities Council Directive of November 24, 1986 (86/609/EEC).

$M D$. The day of birth was designated day 0 . On postnatal day 1 , litters were cross-fostered and culled to six to seven male pups. Random redistribution of pups among dams was done to redistribute possible effects of genetic and prenatal factors and to obtain similar litter size. Two investigators collaborated in the determination of each pup's sex, and each pup received similar handling during this procedure. The litters were each assigned to an experimental group. From day 1, mothers were removed from their home cage and put in a new cage for $3 \mathrm{~h}$, the same procedure being applied at each deprivation. Neonates belonging to the MD group (D) were placed individually in temperature-controlled (30$34^{\circ} \mathrm{C}$ ) and humidity-controlled cages divided into compartments in a room separated from their mothers. The pups' cages contained $2 \mathrm{~cm}$ of fresh shavings covered with absorbing paper. Pups were isolated daily from days 1 to 14 , always from 1:00 to 4:00 P.M. At the end of the deprivation period, each litter was replaced in the housing cage and the dam was transferred back to the housing cage. To reduce handling to a minimum, pups were transferred from and to their cages quickly and gently. D pups received no other handling except that required to change the bedding in their cages once per week. Rat pups not subjected to MD (ND group) remained with their mothers during this period and received no special handling other than that necessary to change the bedding in their cages once per week. From days 15 to 21, all pups remained with their mothers. On day 21 or 22 , pups were weaned from their mothers and housed in groups of three or four until 2.5-3 months of age.

Place-preference paradigm. The place-preference apparatus consisted of a Plexiglas box divided into two square compartments $(45 \times 45 \times 30$ $\mathrm{cm}$; width $\times$ length $\times$ height), $14 \mathrm{~cm}$ from each other, and both accessible from a rectangular exterior area $(18 \times 36 \times 30 \mathrm{~cm}$; width $\times$ length $\times$ height) (Valverde et al., 1997). The box was placed in a soundproof testing room with white noise to mask external noises and illuminated ( 25 lux) by two indirect lights. Two distinctive sensory cues differentiated the compartments: the wall and floor coloring (black or striped) and the floor texture (rough or smooth). The combinations were as follows: (1) black wall, grid floor; and (2) striped wall, smooth floor; naive rats spent approximately the same amount of time in each of the two compartments. The neutral area to access the compartments had gray walls and a gray floor and was at the same elevation as the other two compartments. The position of the rat was recorded by a video camera, and time spent in each compartment was analyzed by a program provided with the Videotrack II version 2.12 computer (Viewpoint, Lyon, France). The rat was scored as being within a compartment if the head and both forepaws were in that area.

One compartment was chosen randomly to be associated with morphine administration; the other compartment was associated with saline administration. The drug-assigned compartment could be either the more or the less preferred. Care was taken to ensure that all treatments were equally balanced between compartments. Experiments were conducted between 9:00 A.M. and 7:00 P.M.

The place-preference conditioning schedule consisted of four phases:

(1) In the preconditioning phase, rats were placed in the middle of the neutral area, and the time spent in each compartment was recorded for the next $20 \mathrm{~min}$. Rats showing strong unconditioned aversion $(<25 \%$ of the session time) or preference ( $>75 \%$ of the session time) for any compartment were discarded ( 4 of 80 ). Rats were then randomized to treatment or control groups and to one of the two compartments.

(2) The conditioning phase consisted of 6 consecutive days of injection. Treated rats received morphine $(2 \mathrm{mg} / \mathrm{kg}$, i.p.) on days 1,3 , and 5 and saline $(1 \mathrm{ml} / \mathrm{kg}$, i.p.) on days 2,4 , and 6 . Control rats received saline every day. The rats were confined to the compartment by a matching door for the $25 \mathrm{~min}$ immediately after the morphine or saline injection. The same procedure was used in another experiment with morphine at the dose of $5 \mathrm{mg} / \mathrm{kg}$ (intraperitoneally).

(3) In the testing phase, the test was conducted exactly as in the preconditioning phase: on day $8,24 \mathrm{~h}$ after the final conditioning session, the rats were given ad libitum access to each compartment for $20 \mathrm{~min}$.

(4) The extinction phase was conducted exactly as the testing phase (day 8 ) but 24 (day 9) and 48 (day 10) hours later.

A place-preference score was calculated as the difference between the postconditioning and preconditioning times spent in the compartment associated with drug. The mean \pm SEM was calculated in each treated or saline group.

Morphine solution consumption. This experiment was performed to measure the consumption of morphine solution in ND and D rats using a two-bottle-choice paradigm, in which one bottle contained water and the other bottle contained morphine $(25 \mathrm{mg} / \mathrm{L})$. No sucrose was added in the morphine solution. The rats were housed in a single cage, received standard diet ad libitum, and were first trained to consume water in the two-bottle-choice paradigm for $5 \mathrm{~d}$ to habituate the rats to the free choice. A bottle of water was then replaced by a bottle of morphine solution for 12 weeks. The bottles were reversed twice per week to control for side preference, and all drinking fluids were completely replaced each week. The consumption in milliliters was measured every 5 of $7 \mathrm{~d}$. The results of morphine consumption were expressed as milligrams of morphine per kilogram for $24 \mathrm{~h}$. The preference ratios were calculated as the percentage of the volume of morphine consumed (milliliters per $24 \mathrm{~h}$ ) divided by the total fluid intake (milliliters per $24 \mathrm{~h}$ ).

Sucrose solution consumption. This experiment was performed to measure the consumption of sucrose solution in ND and D rats using a two-bottle-choice paradigm in which one bottle contained water and the other bottle contained sucrose. The rats were housed in a single cage, received standard diet ad libitum, and were first trained to consume water in the two-bottle-choice paradigm for $7 \mathrm{~d}$ to habituate the rats to the free choice. A bottle of water was then replaced by a bottle of sucrose solution. The bottles were reversed twice per week to control for side preference, and all drinking fluids were completely replaced each week.

The experiment consisted of measuring continuous ad libitum access self-administration of $0.025 \%$ sucrose solution for $90 \mathrm{~d}$. This concentra- 
tion was chosen because a previous experiment in the laboratory showed a preference of $\sim 70 \%$, allowing us to reveal an increase or a decrease in sucrose consumption. In addition, $0.1,0.25,1,2.5,5,10$, and $20 \%$ sucrose induced a high preference of $85-95 \%$ both in ND and D rats (V. Vazquez, B. Giros, and V. Daugé, unpublished results). The consumption in milliliters was measured every 5 of $7 \mathrm{~d}$ most of the time.

The results of sucrose consumption were expressed as a preference for sucrose. The preference ratios were calculated as the percentage of the volume of sucrose consumed (milliliters per $24 \mathrm{~h}$ ) divided by the total fluid intake (milliliters per $24 \mathrm{~h}$ ).

Tissue section preparation for in situ hydridization. All animals were killed under a deep anesthesia ( $200 \mathrm{mg} / \mathrm{kg}$ pentobarbital, i.p.). The brains were removed, quickly frozen by immersion in isopentane at $-20^{\circ} \mathrm{C}$, and stored at $-80^{\circ} \mathrm{C}$ until sectioning. Rostrocaudal series of coronal sections (20 $\mu \mathrm{m}$ thickness) were cut in a cryostat (Leitz, Wetzlar, Germany) according to the frontal plan of the stereotaxis atlas of Paxinos and Watson (1986). For the PPE mRNA quantification, slices were cut as follows. For the structures analyzed in the anterior part of the brain, slices were cut every $200 \mu \mathrm{m}$ from level +3.0 to $+1.0 \mathrm{~mm}$ anterior to bregma. This procedure allowed the study of the PPE mRNA distribution in the N.Acc. and in the anterior part of the dorsal striatum. For the structures analyzed in a more posterior part of the brain, slices were cut every $400 \mu \mathrm{m}$ from -0.8 to $-4.0 \mathrm{~mm}$ posterior to bregma. These slices allowed the analysis of the mRNA distribution in the posterior part of the striatum and the amygdala. Slices were thaw mounted on Superfrost ${ }^{\star} /$ P̈lus slides (MenzelGlass, Braunschweig, Germany). Sections stored at $-80^{\circ} \mathrm{C}$ for no more than 1 week were fixed with $4 \%$ paraformaldehyde in PBS $(0.1 \mathrm{M}$ $\mathrm{NaH}_{2} \mathrm{PO}_{4} / \mathrm{Na}_{2} \mathrm{HPO}_{4}$ and $\left.0.9 \% \mathrm{NaCl}, \mathrm{pH} 7.4\right)$ at $4^{\circ} \mathrm{C}$ for $5 \mathrm{~min}$. They were then rinsed twice with PBS; progressively dehydrated in 50, 70, and $95 \%$ $2 \times$ ethanol; and stored at $4{ }^{\circ} \mathrm{C}$ in $95 \%$ ethanol diluted with sterile water RNase-free treated with $0.1 \%$ diethylpyrocarbonate (Sigma, St. Louis, $\mathrm{MO}$ ) until the in situ hybridization step.

In situ hybridization procedure with oligonucleotide probes. The synthetic DNA oligonucleotide probe was used for hybridization studies. The PPE probe was a 45-mer complementary to nucleotides $147-103$ of the rat PPE mRNA (Howells et al., 1984). The PPE probe was obtained from Genset (Paris, France). Using a database server (Bisance), we checked that the selected sequence only recognized the corresponding mRNAs. No homology $(>72 \%)$ was found in other genes presently cloned (EMBL version 35; 119,518 sequence) in mammals.

In situ hybridization experiments were performed as described previously by Mathieu-Kia and Besson (1997). The oligonucleotide probe was labeled at the $3^{\prime}$ terminus with $\left[{ }^{35} \mathrm{~S}\right] \mathrm{dATP}(1000 \mathrm{Ci} / \mathrm{mmol}$; Amersham Biosciences, Les Ulis, France) by terminal deoxynucleotide transferase. The average specific activity of the probe was $1-2 \times 1-10^{8} \mathrm{dpm} / \mu \mathrm{g}$. The radiolabeled DNA probe was precipitated in $75 \%$ ethanol and $0.4 \mathrm{M} \mathrm{NaCl}$ at $-30^{\circ} \mathrm{C}$. After centrifugation, the pellet was dissolved in $50 \%$ stock hybridization buffer [ $4 \times$ SSC, $1 \times$ Denhardt's solution $(0.02 \%$ ficoll, $0.02 \%$ polyvinylpyrrolidone, and $0.02 \%$ bovine serum albumin), $1 \%$ $\mathrm{N}$-lauroyl-sarcosine, $0.5 \mathrm{mg} / \mathrm{ml}$ denatured salmon sperm DNA, 0.25 $\mathrm{mg} / \mathrm{ml}$ yeast tRNA, $0.25 \mathrm{mg} / \mathrm{ml}$ polyadenosine, and $10 \%$ dextran sulfate], to which freshly prepared $0.1 \mathrm{M}$ dithiothreitol (DTT) was added. The optimal concentration of the radiolabeled probe was determined in previous experiments and corresponded to that giving the best relationship of signal to noise (Mathieu-Kia and Besson, 1997). The radiolabeled oligonucleotide solution ( $30 \mu \mathrm{l} / \mathrm{section})$ was set over sections that were coverslipped with Parafilm and incubated $17-18 \mathrm{~h}$ in humidified chambers at $48^{\circ} \mathrm{C}$. After hybridization, slices were immersed briefly in a $4 \times$ $\mathrm{SSC} / 1 \mathrm{~mm}$ DTT solution to remove the coverslips and washed three times for $15 \mathrm{~min}$ in $2 \times \mathrm{SSC} / 1 \mathrm{~mm}$ DTT, twice for $15 \mathrm{~min}$ in $1 \times \mathrm{SSC} / 0.5 \mathrm{~mm}$ DTT, and twice for $15 \mathrm{~min}$ in $0.5 \times \mathrm{SSC} / 0.25 \mathrm{~mm}$ DTT at $48^{\circ} \mathrm{C}$. After quick rinses at room temperature in $0.5 \times$ SSC/0.25 mM DTT followed by sterile double-distilled water, the slices were progressively dehydrated, air dried, and exposed to $\beta$ max Hyperfilm (Amersham Biosciences) for $6-8 \mathrm{~d}$.

Regional analysis of $m R N A s$. In ND and D rats, quantitative analyses were performed on autoradiographic films using a computerized image analyzer (Autorad; IMSTAR, Paris, France). ND and D rat analyses were processed in parallel. The hybridization signals were quantified in both hemispheres by optical density measurements determined at various rostrocaudal planes taken between +3.0 and $-4.0 \mathrm{~mm}$ relative to bregma according to the atlas of Paxinos and Watson (1986). PPE hybridization signals were quantified in the N.Acc., in the anterior and posterior parts of the dorsal striatum, in the central nucleus, and in the basolateral nuclear complex of the amygdala. In the N.Acc., the four subregions studied were analyzed from three to six sections [from anterior $(\mathrm{A})=$ +2.8 to $\mathrm{A}=+2.2$ for the rostral pole and from $\mathrm{A}=+2.0$ to $\mathrm{A}=+1$ for the core, the cone, and the ventral shell]. The anterior part of the dorsal striatum was analyzed from six sections (from $\mathrm{A}=+2.0$ to $\mathrm{A}=+1$ ), whereas its posterior part was analyzed from five to six sections (from $\mathrm{A}=-0.8$ to $\mathrm{A}=-3.2$ ). In the amygdala, the central nucleus and the basolateral nuclear complex were analyzed from two to four slices (from $\mathrm{A}=-2.0$ to $\mathrm{A}=-3.2$ from bregma). For each section, the local background was subtracted from the value obtained in each hemisphere. The values obtained in both hemispheres were then averaged. For each region, a mean optical density was calculated per animal, and a mean optical density \pm SEM was calculated for each group of rats.

$\mu$-Opioid receptor autoradiography. ND and D rats were killed by decapitation, and their brains were removed quickly, frozen by immersion in isopentane at $-20^{\circ} \mathrm{C}$, and stored at $-80^{\circ} \mathrm{C}$ until sectioning. Rostrocaudal series of coronal sections ( $10 \mu \mathrm{m}$ thickness) were cut at $-20^{\circ} \mathrm{C}$ in a cryostat (Leica, Nussloch, Germany) according to the frontal plan of the stereotaxis atlas of Paxinos and Watson (1986), thaw mounted on slices (Superfrost ${ }^{*} /$ P̈lus slides; Menzel-Glass), and frozen at $-80^{\circ} \mathrm{C}$ until use. For the caudate-putamen nucleus and the N.Acc., two pairs of slices were cut every $160 \mu \mathrm{m}$ from the level $+1.6 \mathrm{~mm}$ anterior to bregma. For the substantia nigra (SN) and ventral tegmental area (VTA), two pairs of slices were cut every $160 \mu \mathrm{m}$ from the level $-5.3 \mathrm{~mm}$ posterior to bregma. Slices were preincubated in $50 \mathrm{~mm}$ Tris- $\mathrm{HCl}, \mathrm{pH}$ 7.4, three times for $4 \mathrm{~min}$. Slices were incubated in the same buffer containing $3.4 \mathrm{nM}$ $\left[{ }^{3} \mathrm{H}\right]$-DAGO (a selective $\mu$-opioid agonist; Amersham Biosciences) for $1 \mathrm{~h}$. Nonspecific binding was determined in the presence of $10 \mu \mathrm{M}$ naloxone (Sigma). After incubation at room temperature, the slices were rinsed with ice-cold $40 \mathrm{~mm}$ Tris-HCl, $\mathrm{pH}$ 7.4, twice for $5 \mathrm{~min}$, briefly dipped twice in ice-cold distilled water, and dried with cold air (Wang et al., 1991).

Autoradiography was performed by apposing the sections to a BAS TR2025 phosphorimager screen (Fuji Ray Test; Fujifilm, Les Ulis, France) for $15 \mathrm{~d}$. Relative activity [photo-stimulated luminescence (PSL/ $\mathrm{mm}^{2}$ )] was measured using a computer-based image analysis system (Multi Gauge; Fujifilm) after scanning the screen with a BAS 5000 phosphorimager (Fujifilm). Relative activities were quantified in both hemispheres. For each section, the local background was subtracted from the value obtained in each hemisphere. The values obtained in both hemispheres were then averaged. For each region, the relative activity (PSL) was calculated per animal, and a mean of relative activity \pm SEM was calculated in ND rats. For the D rats, the relative activities were converted to the percentage of change from the average of the ND relative activity measurements.

Brain dialysis procedure. Rats were anesthetized with chloral hydrate ( $400 \mathrm{mg} / \mathrm{kg}$, i.p.) and stereotaxically implanted bilaterally with 20 gauge ( $0.9 \mathrm{~mm}$ in external diameter) stainless steel cannula guides $1 \mathrm{~mm}$ above the N.Acc. The coordinates from the atlas of Paxinos and Watson (1986) were as follows: A, + $2 \mathrm{~mm}$; lateral, $1.3 \mathrm{~mm}$ from bregma; ventral (V), -7 $\mathrm{mm}$ from the skull surface. The animals were used 1 week after surgery for microdialysis experiments.

The dialysis probes consisted of a 2.5 -mm-long semipermeable polyacrylonitrile AN69 membrane, with a molecular size cutoff of 40,000 Da and an external diameter of $0.3 \mathrm{~mm}$ (a generous gift from Hospal, Lyon, France), connected to a perfusion system described previously by Ladurelle et al. (1997).

The probes were inserted into the chronically implanted cannula guides and positioned so that the active membrane crossed the N.Acc. $(\mathrm{V}=-8 \mathrm{~mm})$. The probes were maintained in position by a locking screw. This was done $14-15 \mathrm{~h}$ before the experiment, and the rats were put into individual black boxes $(40 \times 40 \times 40 \mathrm{~cm})$ with ad libitum access to food and water to habituate the animals to this new environment and to the connection system of the dialysis. The probes were not perfused 
during the $14-15 \mathrm{~h}$ postimplantation period. During the experiments, the microdialysis probes were connected to a microinjection pump (Precinorm; Infors, Bottmingen, Switzerland) via a double-channel liquid swivel. The probes were perfused at the flow rate of $2 \mu \mathrm{l} / \mathrm{min}$ with dialysis buffer (120 mM NaCl, $5 \mathrm{~mm} \mathrm{KCl}, 1.8 \mathrm{~mm} \mathrm{CaCl}_{2}, 1.2 \mathrm{~mm} \mathrm{MgCl}_{2}, 0.01 \%$ BSA, and 0.2 mм PBS, pH 7.4).

After $2 \mathrm{~h}$ of perfusion, four samples were collected for $30 \mathrm{~min}$ each in tubes maintained in dry ice. The samples were maintained at $-20^{\circ} \mathrm{C}$ until the quantification of Met-LI.

RIA of Met-LI. The quantification of Met-LI levels in the dialysate samples was performed as described previously by Daugé et al. (1999). All of the reagents were diluted in phosphate buffer $(10 \mathrm{~mm}$ disodium phosphate, $150 \mathrm{~mm} \mathrm{NaCl}, 1 \mathrm{~g} / \mathrm{L} \mathrm{BSA}$, and $0.1 \mathrm{~g} / \mathrm{L} \mathrm{NaN}_{3}, \mathrm{pH}$ 7.2). Fifty microliters of the antibody dilution $(75,000), 50 \mu \mathrm{l}$ of the $\left[{ }^{125} \mathrm{I}\right]$ Metenkephalin probe $(45,000 \mathrm{cpm} / \mathrm{ml})$, and $60 \mu \mathrm{l}$ of the standard Metenkephalin or biological samples were used. After $44 \mathrm{~h}$ of incubation at $4^{\circ} \mathrm{C}$, the assay was stopped by adding $500 \mu \mathrm{l}$ of phosphate buffer containing $40 \mathrm{~g} / \mathrm{L}$ charcoal SXX extra, $4 \mathrm{~g} / \mathrm{L}$ dextran T70, and 10\% filtered horse serum. After centrifugation $\left(4000 \mathrm{rpm}, 10 \mathrm{~min}, 4^{\circ} \mathrm{C}\right),\left[{ }^{125} \mathrm{I}\right]$ Metenkephalin bound to the antibodies was measured in the supernatant by gamma spectrometry using a PerkinElmer Life Sciences (Zaventem, Belgium) counter. Under these conditions, $0.1 \mathrm{pg}(0.17 \mathrm{fmol})$ of Metenkephalin could be estimated quantitatively in dialysates (Cupo and Jarry, 1985). The Met-enkephalin antiserum has very low cross-reactivity with other opioid peptides (Cupo and Jarry, 1985).

Experimental procedures. One group of adult rats was used for the in situ hybridization experiments (ND, $n=5 ; \mathrm{D}, n=7$ ) and for the dialysis experiments (ND, $n=5 ; \mathrm{D}, n=6)$. A second group of adult rats was used to analyze the reinforcing effects of $2 \mathrm{mg} / \mathrm{kg}$ morphine (ND, $n=20 ; \mathrm{D}$, $n=18$ ), and a third group (ND, $n=19 ; \mathrm{D}, n=19$ ) was used to analyze the reinforcing effects of $5 \mathrm{mg} / \mathrm{kg}$ morphine in the place-preference paradigm. A fourth group of adult rats was used to analyze the extinction of morphine $(2 \mathrm{mg} / \mathrm{kg})$-induced place preference (ND, $n=14 ; \mathrm{D}, n=12)$, and a fifth group was used to analyze the extinction of morphine (5 $\mathrm{mg} / \mathrm{kg}$ )-induced place preference (ND, $n=20 ; \mathrm{D}, n=20)$. A sixth group of adult rats was used for the $\mu$-opioid receptor binding experiment (ND, $n=8 ; \mathrm{D}, n=6)$ and for the oral morphine self-administration study $(\mathrm{ND}, n=9 ; \mathrm{D}, n=9)$. A seventh group of adult rats was used to analyze oral sucrose self-administration ( $\mathrm{ND}, n=8 ; \mathrm{D}, n=6)$. Each rat was used only once.

Histological control. After microdialysis experiments, rats were killed with an overdose of chloral hydrate and decapitated. The brains were removed and frozen in isopentane solution at $-35^{\circ} \mathrm{C}$. They were cut on a microtome, and the slices $(30 \mu \mathrm{m})$ were stained with cresyl violet. The position of the probes was estimated according to the atlas of Paxinos and Watson (1986). Probes that traversed $>70 \%$ of the N.Acc. were considered to be placed correctly.

Drugs. Morphine $\mathrm{HCl}$ was purchased from Francopia (Paris, France). It was dissolved in $0.9 \%$ saline before use for the experiments of place preference. Morphine was dissolved in tap water $(25 \mathrm{mg} / \mathrm{L})$ for the experiments of morphine solution consumption. Sucrose was purchased from Sigma (St. Quentin Fallavier, France). It was dissolved in tap water for the experiment of sucrose solution consumption.

Statistical analysis. The results of behavioral and biochemical experiments are expressed as means \pm SEM. The results were compared using a parametric ANOVA, followed by Fisher's PLSD test for comparisons with the control group or the Newman-Keuls test for multiple comparisons. For each region of the in situ hybridization experiments, a mean optical density was calculated per animal, and a mean optical density \pm SEM was calculated for each group of rats. For each region of the autoradiography experiment, the relative activity (PSL) was calculated per animal, and a mean of relative activity \pm SEM was calculated in ND rats. For the $\mathrm{D}$ rats, the relative activities were converted to the percentage of change from the average of the ND relative activity measurements. All data were analyzed by one-way ANOVA followed by Fisher's PLSD test. Microdialysis studies and the experiments of morphine and sucrose solution consumptions were analyzed by two-way repeated-measures ANOVA (between-subject for deprivation factor and within-subject for time). If significant effects were obtained, a one-way ANOVA followed
Table 1. Effects of $2 \mathrm{mg} / \mathrm{kg}$ (M2) and $5 \mathrm{mg} / \mathrm{kg}$ (M5) morphine (intraperitoneally) on the expression of the place-preference paradigm in ND and $D$ rats

\begin{tabular}{lcc}
\hline Rats & Treatment & Score \\
\hline ND & Saline & $-20.0 \pm 26.9$ \\
ND & M2 & $-10.7 \pm 22.6$ \\
D & Saline & $64.9 \pm 42.9$ \\
D & M2 & $166.7 \pm 25.7^{*+}$ \\
ND & Saline & $-18.5 \pm 39.8$ \\
ND & M5 & $115.6 \pm 51.8^{*}$ \\
D & Saline & $-28.4 \pm 41.7$ \\
D & M5 & $167.3 \pm 64.6^{*}$
\end{tabular}

During the place-conditioning period, rats received morphine on days 1,3, and 5 and saline on days 2,4 , and 6 immediately before confinement in the associated compartment. Rats were $2.5-3$ months of age. The results are expressed as a score, calculated as the difference between the postconditioning and preconditioning times spent in the compartment associated with the drug (ANOVA; $2 \mathrm{mg} / \mathrm{kg}$; deprivation: $F_{(13,3)}=25.66 ; p<0.0001$; treatment: $F_{(1,34)}=4.27 ; p=0.04 ;$ interaction: $F_{(1,34)}=3.87 ; p=0.05 ; 5 \mathrm{mg} / \mathrm{kg} ;$ deprivation: $F_{(1,34)}=0.042 ; p>0.05$ treatment: $F_{(1,34)}=6.7 ; p=0.01$; interaction: $\left.F_{(1,34)}=1.47 ; p>0.05\right) .{ }^{*} p<0.05$ versus the respective saline group; ${ }^{+} p<0.05$ versus the ND morphine group (Newman-Keuls test).

by the Newman-Keuls test was used to determine the significance at each time point. The $\chi^{2}$ test was used to determine the significance between $\mathrm{ND}$ and $\mathrm{D}$ rats for the number of rats showing a preference for morphine bottle $>50 \%$ for 2 weeks. Two-way ANOVA (deprivation and treatment) or three-way repeated-measures ANOVA (between-subject for deprivation and treatment factors and within-subject for time), followed by a one-way ANOVA and by the Newman-Keuls test, was used for placepreference experiments. All data were analyzed with Statview 5 for Macintosh. The level chosen for statistical significance was 5\%.

\section{Results}

\section{Place-preference paradigm}

Untreated ND and D rats did not show spontaneous preference for one specific compartment (black compartment: ND, $456.5 \pm$ 40.3 s; D, $433.4 \pm 20.9$ s; striped compartment: ND, $420.4 \pm$ $40.1 \mathrm{~s} ; \mathrm{D}, 469.8 \pm 32.1 \mathrm{~s}$ ). Morphine ( $2 \mathrm{mg} / \mathrm{kg}$, i.p.) had no effect on the time spent in the morphine-associated compartment by the ND group $\left(F_{(1,18)}=0.033 ; p>0.05\right)$. In contrast, $\mathrm{D}$ rats receiving $2 \mathrm{mg} / \mathrm{kg}$ morphine spent significantly more time than saline-treated rats in the morphine-associated compartment $\left(F_{(1,16)}=4.722 ; p<0.04\right)$. The effects of $5 \mathrm{mg} / \mathrm{kg}$ morphine (intraperitoneally) were significant. This dose of morphine produced a significant increase in the time spent in the morphineassociated compartment for both the ND and D rats (ND rats: $F_{(1,17)}=4.304 ; p<0.05$; D rats: $F_{(1,17)}=6.474 ; p<0.02$ ) (Table $1)$. This experiment showed that $D$ rats had a higher sensitivity than ND rats to the effects of morphine in the place-preference test.

In a second series of experiment, the extinction of morphineassociated conditioned place preference was evaluated. Similar results as above were observed after 2 and $5 \mathrm{mg} / \mathrm{kg}$ morphine in $\mathrm{ND}$ and $\mathrm{D}$ rats on the day of the test (day 8 ). ND rats did not show morphine conditioning at days 9 and 10, whereas D rats were conditioned with $2 \mathrm{mg} / \mathrm{kg}$ morphine at day $9(p=0.08)$ and conditioned significantly with $5 \mathrm{mg} / \mathrm{kg}$ morphine at day 9 ( $p=$ 0.002 ) and day 10 ( $p=0.02$ ) (Fig. 1). This experiment showed a prolonged morphine conditioning in $\mathrm{D}$ rats.

\section{Measurement of morphine solution consumption}

There was no difference in the total fluid intake between ND and $D$ rats during the experiment $\left(F_{(1,16)}=0.96 ; p>0.05\right)$ (data not shown) and no difference in water consumption between ND and $\mathrm{D}$ rats at the start of the experiment $(\mathrm{ND}, 31.4 \pm 0.6 \mathrm{ml}$;, $31.3 \pm$ $1.0 \mathrm{ml})\left(F_{(1,16)}=0.012 ; p>0.05\right)$.

The long-term course of morphine solution consumption and preference was characterized by a period of relatively stable con- 


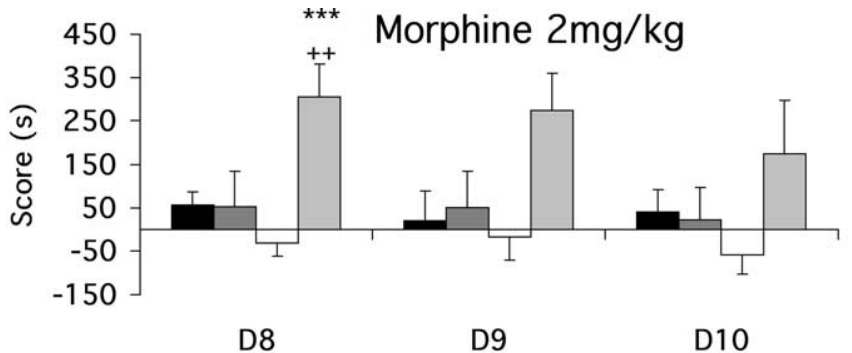

ND saline $\square$ ND morphine $\square$ D saline $\square$ D morphine

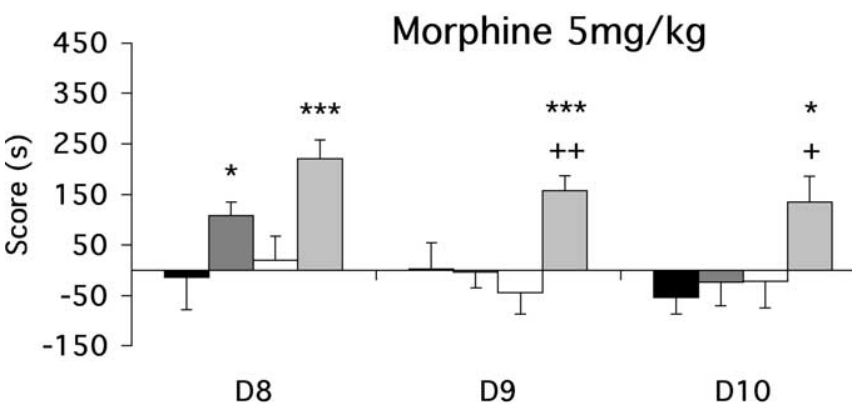

Figure 1. Effects of $2 \mathrm{mg} / \mathrm{kg}$ morphine (ND, $n=14 ; \mathrm{D}, n=12$ ) and $5 \mathrm{mg} / \mathrm{kg}$ morphine (intraperitoneally; $N D, n=20 ; D, n=20$ ) on the expression [day 8 (D8)] and extinction (D9 and D10) periods of the place-preference paradigm in ND and D rats. During the place-conditioning period, rats received morphine on days 1,3 , and 5 and saline on days 2,4 , and 6 immediately before confinement in the associated compartment. Rats were tested at 2.5-3 months of age. The results are expressed as a score (s), calculated as the difference between the postconditioning and preconditioning times spent in the compartment associated with the drug (ANOVA for $2 \mathrm{mg} / \mathrm{kg}$; deprivation: $F_{(1,22)}=1.08 ; p=0.30$; treatment: $F_{(1,22)}=5.07 ; p=0.03$; interaction: $F_{(1,22)}=4.83 ; p=0.03 ;$ time: $F_{(2,44)}=1.91 ; p>0.05$; interactions time-deprivation, time-treatment, and time-deprivation plus treatment, $p>0.05$; ANOVA for $5 \mathrm{mg} / \mathrm{kg}$; deprivation: $F_{(1,36)}=5.04 ; p=0.03$; treatment: $F_{(1,36)}=12.28 ; p=0.001$; interaction: $F_{(1,36)}=$ $4.26 ; p=0.04$; time: $F_{(2,72)}=5.3 ; p=0.007$; interactions time-deprivation, time-treatment, and time-deprivation plus treatment, $p>0.05$ ). Error bars represent SEM. ${ }^{*} p<0.05$, ${ }^{* * *} p<0.001$ versus the respective saline group; ${ }^{+} p<0.05,{ }^{++} p<0.01$ versus 2 or $5 \mathrm{mg} / \mathrm{kg}$ morphine in the ND group (Newman-Keuls test).

sumption and preference at the beginning of the experiment, followed by periods of increase and periods of decrease in ND and $\mathrm{D}$ rats. However, in contrast to ND rats, D animals progressively increased their consumption and preference to reach a plateau.

The long-term course of morphine consumption in D rats was therefore subdivided into three phases: (1) a period of habituation occurred from days 6 to 20 , in which there was no significant increase in morphine solution consumption and preference in D rats; (2) a period of installation occurred from days 21 to 52, characterized by a highly and progressively significant increase in morphine solution consumption and preference in D rats; and (3) a period of plateau occurred from days 53 to 90 , in which a stable consumption was shown in D rats. A significant increase in morphine consumption and preference was observed in D rats compared with ND rats from days 25 to 90 (Fig. $2 A, B$ ).

Means \pm SEM within the three periods were calculated to smooth daily drinking variability. There were no significant effects of time in ND rats (consumption: $F_{(2,24)}=0.45 ; p>0.05$; preference: $\left.F_{(2,24)}=1.58 ; p>0.05\right)$ in contrast to $\mathrm{D}$ rats that showed an increase over time of the morphine solution consumption (Fig. 3) and preference (data not shown) (consumption: $F_{(2,24)}=4.03 ; p=0.03$; preference: $F_{(2,24)}=6.52 ; p=$ $0.005)$.

When rats were categorized according to $>50 \%$ choice for the morphine bottle, $\mathrm{ND}$ and $\mathrm{D}$ rats did not show an initial morphine
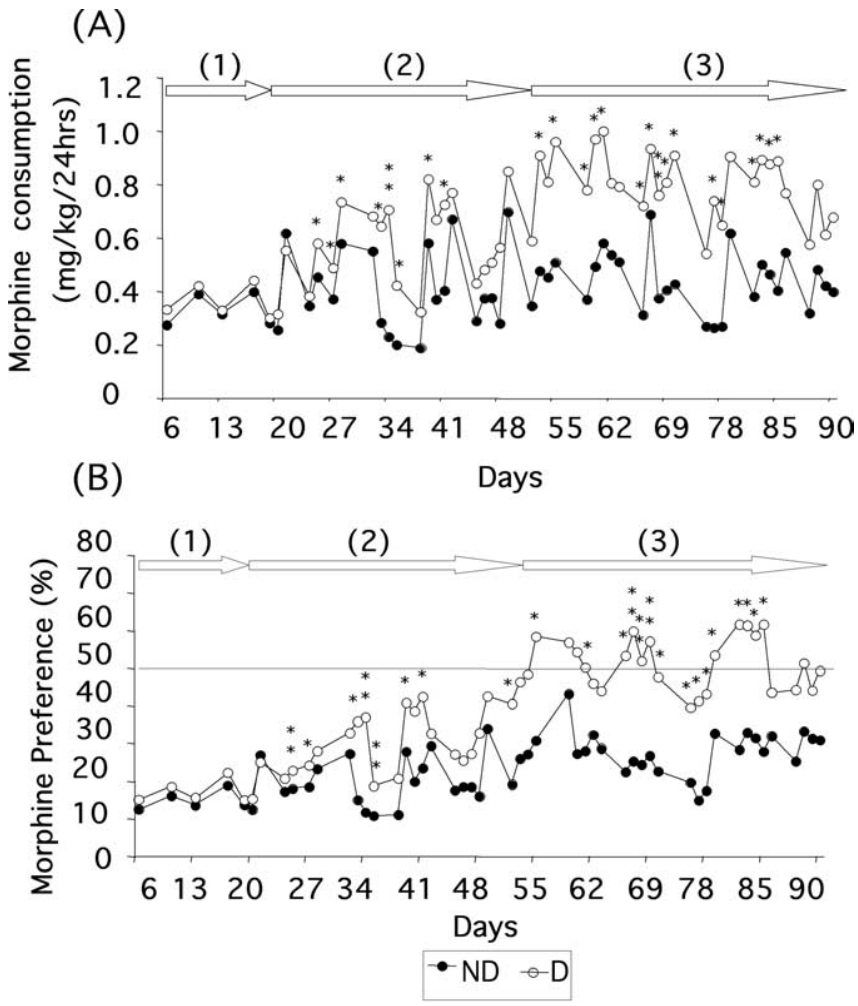

Figure 2. Oral morphine $(25 \mathrm{mg} / \mathrm{L})$ self-administration behavior using the two-bottlechoice paradigm in ND $(n=9)$ and $D(n=9)$ rats for 12 weeks. $A$, Morphine solution consumption. $\boldsymbol{B}$, Morphine preference. The results are expressed as mean. (1), Habituation phase (consumption, deprivation: $F_{(1,16)}=1.62 ; p>0.05 ;$ time: $F_{(5,80)}=7.9 ; p<0.0001$; interaction: $F_{(5,80)}=0.217 ; p>0.05$; preference, deprivation: $F_{(1,16)}=3.13 ; p>0.05$; time: $F_{(5,80)}=$ 9.19; $p<0.0001$; interaction: $\left.F_{(5,80)}=0.16 ; p>0.05\right)$; (2), installation phase (consumption, deprivation: $F_{(1,16)}=5.64 ; p=0.03$; time: $F_{(19,304)}=8.55 ; p<0.0001$; interaction: $F_{(19,304)}$ $=1.64 ; p=0.04$; preference, deprivation: $F_{(1,16)}=5.44 ; p=0.03$; time: $F_{(19,304)}=5.49$; $p<0.0001$; interaction: $\left.F_{(19,304)}=2.0 ; p=0.008\right)$; (3), plateau phase (consumption, deprivation: $F_{(1,16)}=6.37 ; p=0.02 ;$ time: $F_{(25,400)}=3.39 ; p<0.0001$; interaction: $F_{(25,400)}=$ $0.76 ; p>0.05$; preference, deprivation: $F_{(1,16)}=5.73 ; p=0.03$; time: $F_{(25,400)}=2.49 ; p<$ 0.0001 ; interaction: $\left.F_{(25,400)}=1 ; p>0.05\right) .{ }^{*} p<0.05,{ }^{* *} p<0.01$ versus the ND group (Newman-Keuls test).

preference during the first phase of habituation. During the installation phase, $11 \%$ of ND rats and $56 \%$ of D rats showed a preference for morphine solution $\left(\chi^{2}=44.37 ; p<0.0001\right)$, and $22 \%$ of ND rats and $67 \%$ of D rats showed a preference for morphine solution during the plateau phase $\left(\chi^{2}=40.09 ; p<0.0001\right)$ (Fig. 4).

This experiment showed that $\mathrm{D}$ rats progressively increased morphine solution consumption to reach a preference for morphine compared with water, whereas the ND rats showed a stable behavior on morphine solution consumption without preference for morphine solution for 12 weeks.

\section{Measurement of sucrose solution consumption}

There was no difference in total fluid intake between ND and D rats during the experiment $\left(F_{(1,12)}=0.83 ; p>0.05\right)$ (data not shown) and no difference in water consumption between ND and D rats at the start of the experiment $(\mathrm{ND}, 27.3 \pm 1.1 \mathrm{ml} ; \mathrm{D}, 26.0 \pm$ $1.1 \mathrm{ml})\left(F_{(1,12)}=0.617 ; p>0.05\right)$.

The oral sucrose self-administration behavior was studied for $90 \mathrm{~d}$. The sucrose concentration of $0.025 \%$ was chosen because the preference for sucrose was $\sim 70 \%$ in ND and D rats at the start of the experiment (as expected from a preliminary study), allow- 


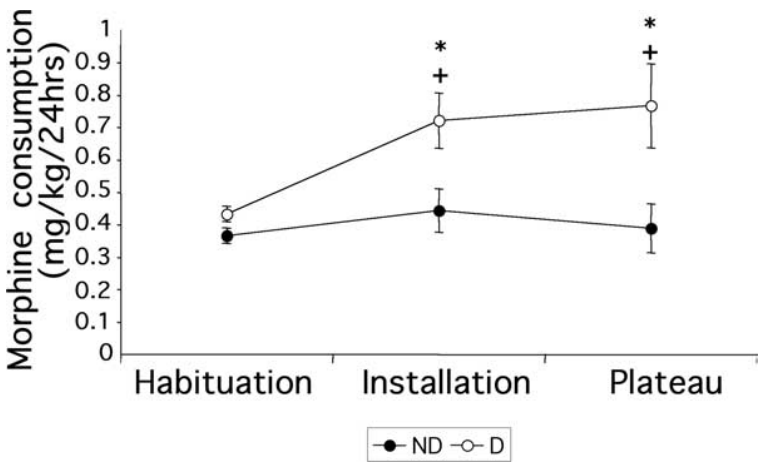

Figure 3. Oral morphine $(25 \mathrm{mg} / \mathrm{L})$ self-administration behavior using the two-bottlechoice paradigm in ND $(n=9)$ and $D(n=9)$ rats for 12 weeks. The long-term course of morphine solution consumption was subdivided into three phases: habituation, installation, and plateau. Means \pm SEM within each of the three periods were calculated to smooth daily drinking variability. Error bars represent SEM. Two-way repeated-measures ANOVA showed significant effects of deprivation, time factors, and interaction (consumption, deprivation: $F_{(1,16)}=7.89 ; p=0.01$; time: $F_{(2,32)}=6.65 ; p=0.003$; interaction: $F_{(2,32)}=3.85 ; p=0.03$; preference, deprivation: $F_{(1,16)}=7.06 ; p=0.01$; time: $F_{(2,32)}=14.18 ; p<0.0001$; interaction: $\left.F_{(2,32)}=3.71 ; p=0.03\right) .{ }^{*} p<0.05$ versus the ND group; ${ }^{+} p<0.05$ versus the $D$ habituation phase (Newman-Keuls test).

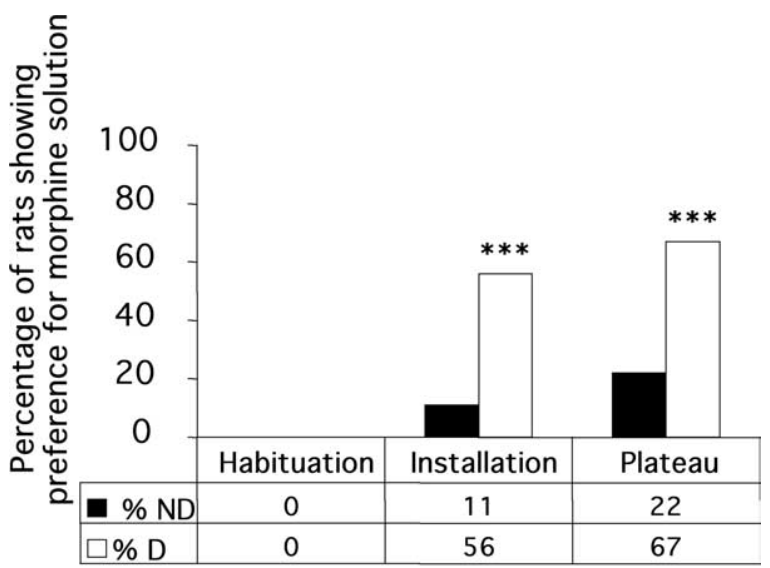

Figure 4. Percentage of ND and D rats showing a preference of $>50 \%$ for the morphine solution during the habituation, installation, and plateau phases. ${ }^{* * *} p<0.001$ versus the ND group ( $\chi^{2}$ test).

ing us to reveal an increase or a decrease in sucrose preference. In addition, $0.1,0.25,1,2.5,5,10$, and $20 \%$ of sucrose induced a high preference of 85-95\% (Vazquez, Giros, and Daugé, unpublished results). The preference of $70 \%$ observed with $0.025 \%$ sucrose indicated that ND and D rats detected a difference between sucrose and water and that the sucrose solution was attractive. Sucrose preference decreased at $\sim 50 \%$ in both groups from days 11 to 34 and remained $\sim 40-50 \%$ for ND rats until the end of the experiment, indicating that this low concentration of sucrose had no reinforcing effects. In contrast, a slight but significant increase in sucrose preference from $\sim 60-70 \%$ was observed in D rats from day 34 until the end of the experiment. A significant increase in sucrose preference was only observed in D rats compared with ND rats from days 47 to 54 and on day 90 (Fig. 5). Consequently, the long-term course of sucrose solution preference in $\mathrm{D}$ rats cannot be subdivided into three phases as for morphine intake. In addition, the difference between ND and D preference $(140 \%)$ was too low to categorize rats as above for morphine, in which the difference reached $250 \%$.

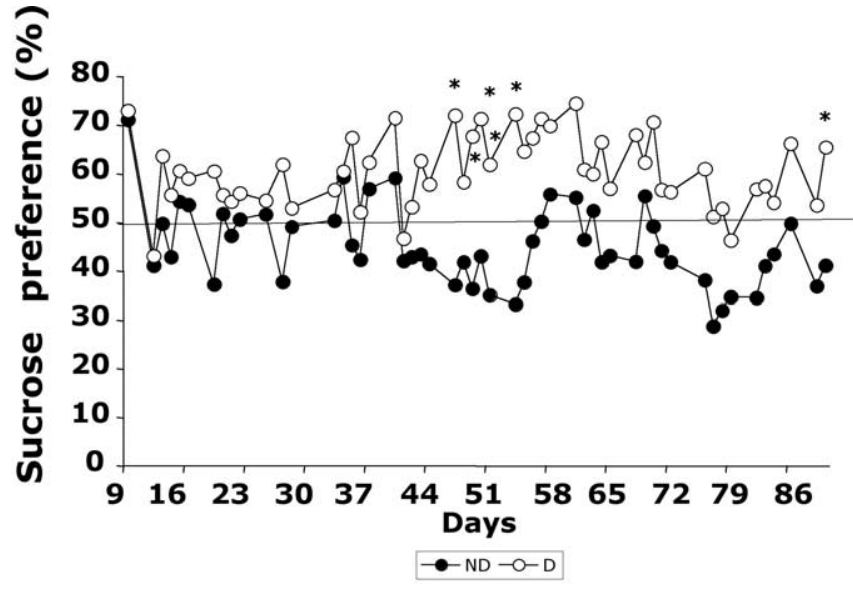

Figure 5. Oral sucrose $(0.025 \%)$ self-administration behavior using the two-bottle-choice paradigm in ND $(n=8)$ and $D(n=6)$ rats for $90 \mathrm{~d}$. The results are expressed as means of preference (ANOVA; deprivation: $F_{(1,12)}=5.69 ; p=0.03$; time: $F_{(53,636)}=1.40 ; p=0.03$; interaction: $\left.F_{(53,636)}=0.64 ; p>0.05\right) .{ }^{*} p<0.05$ versus the ND group (Newman-Keuls test).

These experiments showed that $\mathrm{D}$ rats developed a slight higher preference for sucrose than ND rats.

\section{Effect of MD on PPE mRNA expression in the brain}

There is a decrease in PPE mRNA levels in all examined regions of the N.Acc. of D rats, but this decrease was significant only in the cone $\left(-32 \% ; F_{(1,10)}=5.66 ; p=0.03\right)$ and core $\left(-29 \% ; F_{(1,10)}=\right.$ $5.94 ; p=0.03)$ regions of the N.Acc. (rostral: $F_{(1,10)}=3.43 ; p=$ 0.09; shell: $F_{(1,10)}=3.86 ; p=0.08$ ) (Fig. 6). A significant decrease was also observed in the anterior part of the caudate-putamen nucleus $(-29 \%)$ of D rats compared with ND rats $\left(F_{(1,10)}=6.10\right.$; $p=0.03)$. No significant difference was observed in the posterior caudate-putamen nucleus $\left(1 \% ; F_{(1,10)}=0.004 ; p>0.05\right)$, in the central nucleus $\left(-5 \% ; F_{(1,10)}=0.12 ; p>0.05\right)$, and in the basolateral nuclear complex $\left(-17 \% ; F_{(1,10)}=2.36 ; p>0.05\right)$ of the amygdala (Figs. 6, 7).

\section{$\mu$-Opioid receptor density in the striatum and in the mesencephalon}

The results from quantitative autoradiography of $\mu$-opioid receptor binding showed no significant difference between ND and $D$ rats in the caudate-putamen nucleus $\left(F_{(1,12)}=1.41 ; p>0.05\right)$, in the core $\left(F_{(1,12)}=0.004 ; p>0.05\right)$, in the cone $\left(F_{(1,12)}=0.479\right.$; $p>0.05)$, in the shell $\left(F_{(1,12)}=0.001 ; p>0.05\right)$ of the N.Acc., in the SN $\left(F_{(1,12)}=1.54 ; p>0.05\right)$, and in the VTA $\left(F_{(1,12)}=0.005\right.$; $p>0.05)$. In the caudate-putamen nucleus, the typical patches of high labeling density observed with $\left[{ }^{3} \mathrm{H}\right]$-DAGO did not differ between ND and D rats $\left(F_{(1,12)}=0.034 ; p>0.05\right)$ (Table 2, Fig. 8).

\section{Effects of MD on the extracellular levels of Met-LI in the N.Acc.}

Microdialysis experiments performed in freely moving rats showed that the basal extracellular levels of Met-LI in ND animals were quite similar to those obtained in a previous study using Wistar rats (Daugé et al., 1999). In contrast, the basal extracellular levels of Met-LI in the N.Acc. of D rats were significantly decreased compared with ND rats (Fig. 9).

\section{Discussion}

These data show that MD leads to a hypersensitivity to the reinforcing effects of morphine, to the development of morphine and 


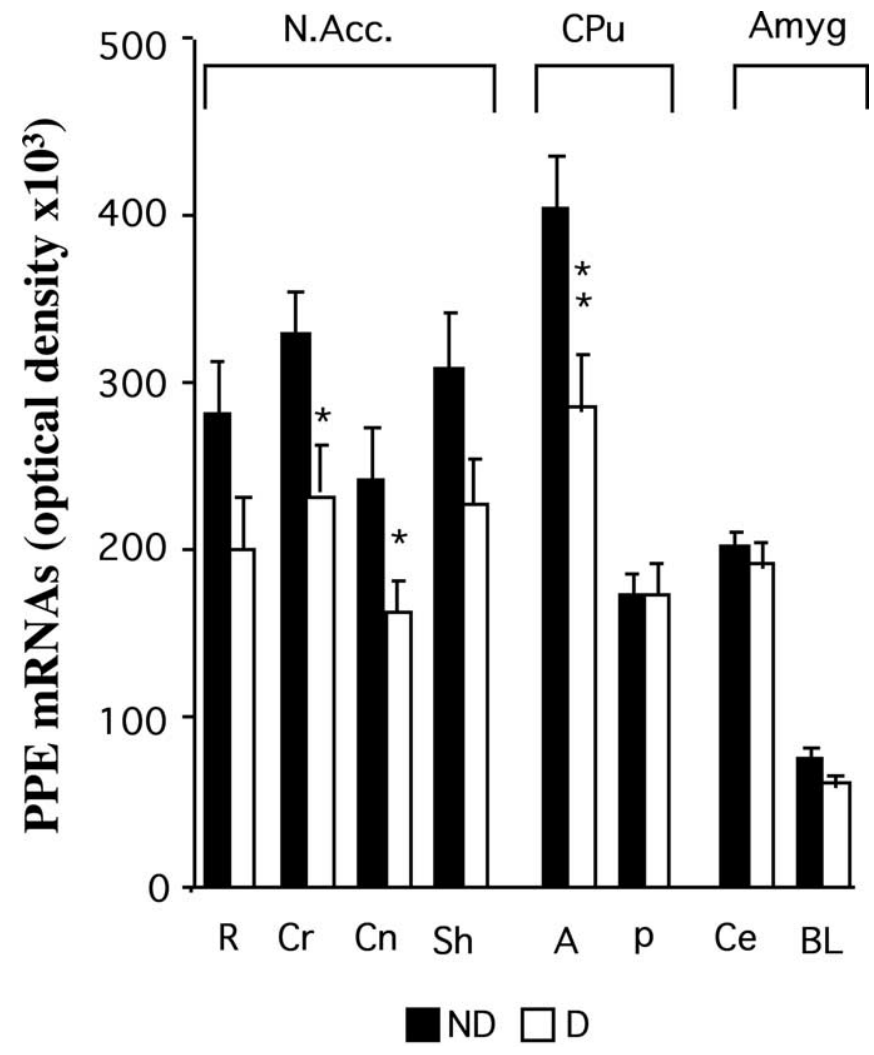

Figure 6. PPE mRNA hybridization signals in the rostral $(\mathrm{R})$, core $(\mathrm{Cr})$, cone $(\mathrm{Cn})$, and shell (Sh) parts of the N.Acc.; in the anterior (A) and posterior (p) caudate-putamen nucleus ( $\mathrm{CPu}$ ) and in the central (Ce) and basolateral (BL) nucleus of the amygdala (Amyg) of ND ( $n=5)$ and $D(n=7)$ rats. Rats were killed at 3 months of age. Values correspond to mean optical density $\times 10^{3} \pm$ SEM. Error bars represent SEM. ${ }^{*} p<0.05,{ }^{* *} p<0.01$ versus the ND group (Fisher's PLSD test).

sucrose dependence, and to a hypoactivity of the enkephalinergic system in adult rats.

The rewarding and reinforcing effects of drugs can be studied in the place-preference paradigm. The conditioning effects of morphine as well as extinction of this behavior were analyzed in ND and D rats. The extinction of drug-associated conditioned cues is presumed to be primarily responsible for craving and relapse in drug-free former addicts (for review, see Tzschentke, 1998). We observed in two separated experiments that $5 \mathrm{mg} / \mathrm{kg}$ morphine induced place conditioning in ND and D rats, but for the lower dose of $2 \mathrm{mg} / \mathrm{kg}$ morphine, place conditioning was observed only in $\mathrm{D}$ rats. Interestingly, the extinction of morphine-induced place conditioning $(5 \mathrm{mg} / \mathrm{kg}$ ) occurred as early as the day after the test (day 9) in ND rats, whereas condi-
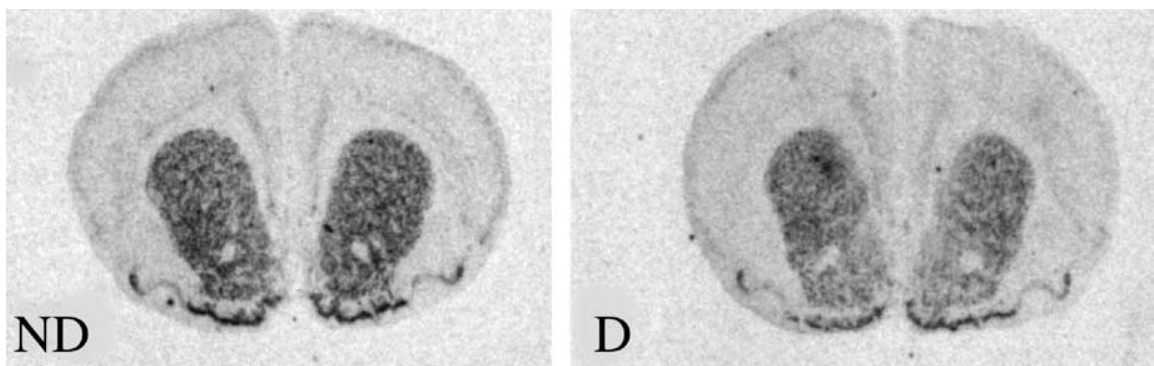

Figure 7. Autoradiograms of frontal brain sections showing the distribution of PPE mRNA expression in the striatum of ND and Drats. tioning was still highly significant at days 9 and 10 in D rats. For the lower dose of $2 \mathrm{mg} / \mathrm{kg}$, increased preference for the morphine-associated compartment was observed in $\mathrm{D}$ rats but did not reach significance. Thus, D rats are more sensitive to the reinforcing effects of morphine and showed more prolonged morphine conditioning. Supporting these results, recent data showed that MS increases sensitivity to the withdrawal syndrome and antinociceptive tolerance to chronic morphine (Kalinichev et al., 2001, 2002).

Because of the hypersensitivity to the reinforcing effects of morphine in D rats, it was complementary to study the behavior of these animals facing morphine solution in a two-bottle-choice paradigm. It was shown that a progressive increase in morphine consumption in D rats reached a preference for morphine (50\%), whereas ND rats had a stable behavior without preference for morphine (20-30\%) during 12 weeks. The morphine consumption of D rats was twice higher than that of ND rats at the plateau phase. An analysis of the daily intake of morphine across the 12 weeks showed that both groups initially presented an avoidance for the morphine solution compared with water. This is in agreement with other studies in which sucrose was not added to the solution and is substantiated by the aversive taste of morphine (for review, see Wolffgramm and Heyne, 1995). Afterward, mean intake remained unpredictable with high-intake periods, which were followed by days with low intake as described previously (McLachlan et al., 1994; for review, see Wolffgramm and Heyne, 1995). This behavior observed in both groups of animals was reported previously and interpreted as a progressive learning process involving both classical and operant conditioning, the latter component taking more time than classical conditioning to develop long-term stable behavior (for review, see Wolffgramm and Heyne, 1995). In contrast to the relatively stable consumption in ND rats and despite the aversive taste of the morphine, $\mathrm{D}$ rats developed a preference for morphine (from 20 to 50\%). This evolutive pattern of morphine daily consumption refutes a possibility that MD could change the biological circuitry of taste sensing in $\mathrm{D}$ rats rendering morphine taste less aversive, as reported for the case of sweetened water in maternally deprived monkeys (Paul et al., 2000). Another important aspect was the proportion of rats that reached $>50 \%$ choice for the morphine bottle for at least 2 weeks (i.e., $11 \%$ of ND rats and $56 \%$ of D rats at the installation phase and $22 \%$ of ND rats and $67 \%$ of D rats at the plateau phase). Interestingly, this proportion of ND rats reaching the criteria of $50 \%$ of morphine preference is highly similar to the percentage of rats (17\%) that show a high score for addiction-like criteria in a recent study (Deroche-Gamonet et al., 2004). In contrast, the proportion of $\mathrm{D}$ rats reaching $>50 \%$ choice for morphine rose to $65 \%$. This indicates that MD constitutes a risk factor that might be able to accelerate, facilitate, or even induce an addiction. However, it remains to be clarified whether $\mathrm{D}$ rats present a loss of control and of reversibility, which are two major features of addiction according to the Diagnostic and Statistical Manual of Mental Disorders, fourth revision (2000).

The hypersensitivity to morphine shown in the place-preference paradigm and the development of morphine dependence in $\mathrm{D}$ rats could be the consequence of a dysfunction of the enkephalinergic system.

We tested this hypothesis by studying 
Table 2. Quantitative autoradiography of $\mu$-opioid receptor binding $\left[{ }^{3} \mathrm{H}\right]-\mathrm{DAGO}$ in the striatum and mesencephalon of ND and $\mathrm{D}$ rats

\begin{tabular}{|c|c|c|c|c|c|c|c|}
\hline \multirow[b]{2}{*}{ Rats } & \multirow[b]{2}{*}{$\mathrm{CPu}$} & \multirow[b]{2}{*}{ Patch } & \multicolumn{3}{|l|}{ N. Acc. } & \multirow[b]{2}{*}{ SN } & \multirow[b]{2}{*}{ VTA } \\
\hline & & & Core & Cone & Shell & & \\
\hline ND & $1 \pm 0.04$ & $1 \pm 0.03$ & $1 \pm 0.06$ & $1 \pm 0.05$ & $1 \pm 0.03$ & $1 \pm 0.12$ & $1 \pm 0.14$ \\
\hline D & $0.94 \pm 0.04$ & $1.01 \pm 0.07$ & $1 \pm 0.04$ & $1.07 \pm 0.09$ & $1 \pm 0.04$ & $1.25 \pm 0.13$ & $1.03 \pm 0.09$ \\
\hline
\end{tabular}

$\mathrm{CPu}$, Caudate-putamen. The results are expressed as mean \pm SEM of the percentage of change from the average of the ND relative activity (PSL).
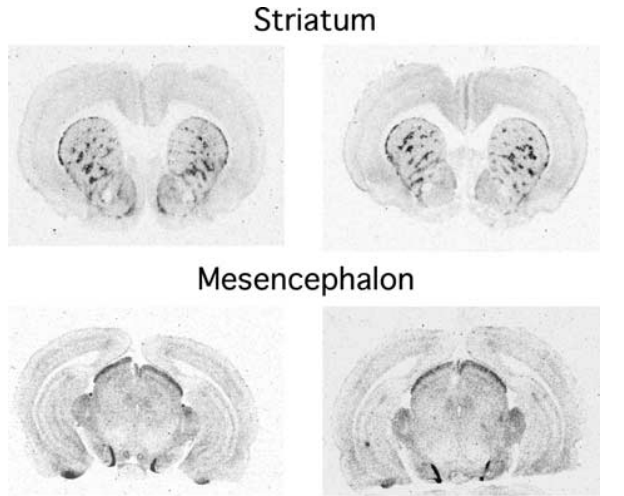

ND

D

Figure 8. Autoradiograms of frontal brain sections showing the distribution of $\mu$-opioid receptor binding $\left.\left({ }^{3} \mathrm{H}\right]-\mathrm{DAGO}\right)$ in the striatum and the mesencephalon of $\mathrm{ND}$ and $\mathrm{D}$ rats.

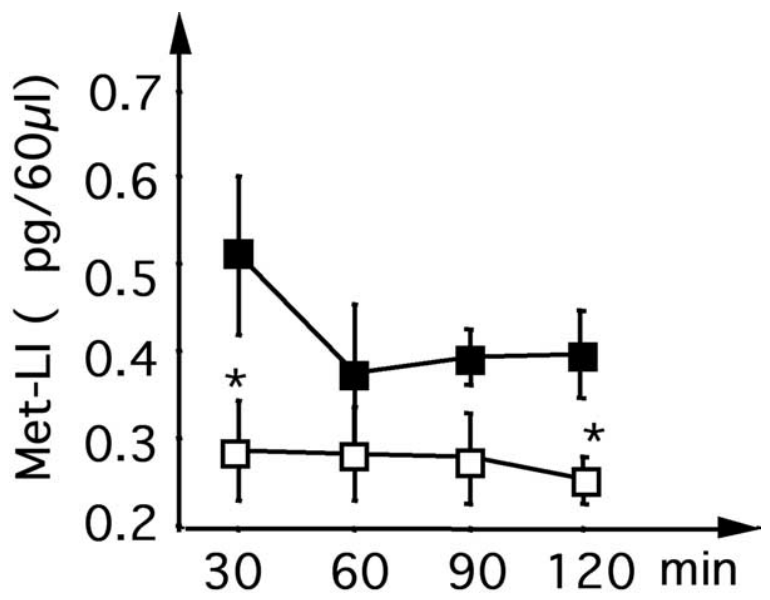

Figure 9. Extracellular levels of Met-Ll in the N.Acc. of ND $(n=5 ; \square)$ and $D(n=6 ; \square)$ rats. Values correspond to mean $\pm \mathrm{SEM}\left(\mathrm{pg} / 60 \mu \mathrm{l}\right.$; ANOVA; deprivation: $F_{(1,9)}=5.25 ; p<0.05$; time: $F_{(3,27)}=1.12 ; p>0.05$; interaction: $\left.F_{(3,27)}=0.90 ; p>0.05\right)$. Error bars represent SEM. ${ }^{*} p<0.05$ versus the ND group (Newman-Keuls test).

the state of this endogenous neurotransmission at the transcriptional (PPE mRNA), translational ( $\mu$-opiate receptor binding), and functional (Met-enkephalin, microdialysis) levels. A decrease in PPE mRNA levels in the N.Acc. and in the anterior part of the caudate-putamen nucleus was observed in D rats compared with ND rats. In the N.Acc. a similar decrease in PPE mRNA levels was observed in the four main subregions (rostral pole, core, cone, shell) of D rats compared with ND rats with a significant decrease in the cone and core of the nucleus. In contrast, no modification of PPE mRNAs levels was found in the posterior caudate-putamen nucleus and in the amygdala, indicating that MD produced a regional dysfunction of the enkephalinergic system as suggested previously (Daugé, 2002).

The decrease in PPE mRNA levels in the striatum of D rats could be a direct or indirect consequence of MD. Indeed, a de- crease in PPE mRNAs as a consequence of an increase in the activity of dopaminergic systems was reported in mice lacking the dopamine (DA) transporter (Giros et al., 1996) or after chronic treatments with $\mathrm{D}_{2}$ receptor agonists (Caboche et al., 1991; Gerfen et al., 1991). Moreover, hypersensitivity to psychostimulant effects on locomotor activity and on the acquisition of cocaine self-administration was reported after MS (Kosten et al., 2000; Meaney et al., 2002) and MD (Pryce et al., 2001). However, the opposite was also found after MS (for review, see Matthews and Robbins, 2003). In addition, morphine induced conditioned place preference via DA-independent or DA-dependent mechanisms in the N.Acc. (Shippenberg et al., 1993; Sellings and Clarke, 2003). Additional studies are now in progress in the laboratory to elucidate this hypothesis.

This study also shows a decrease in the basal extracellular levels of Met-LI in the N.Acc. of D rats. This is in contrast to the lack of changes of opioid peptide levels in the striatum of separated rats published recently (Ploj et al., 2003b). However, the discrepancies could be explained by the differences in the methodology used (the protocol of separation, the peptides measured, cerebral regions vs subregions studied, global vs extracellular levels of peptide measured). In addition, the same relationship between a decrease in PPE mRNAs, in opioid peptides, and the development of morphine dependence was described in Lewis rats (Nylander et al., 1995; Martin et al., 1999).

The hypersensitivity of $\mathrm{D}$ rats to morphine could be the consequence of the hypoactivity of the enkephalinergic system and thus hypersensitivity of $\mu$-opioid receptors. The autoradiography of $\mu$-opioid receptor binding showed no difference in the caudate-putamen nucleus, the N.Acc., the SN, and the VTA between ND and D rats. In the same manner, no changes of opioid receptor densities were observed in the striatum and the mesencephalon of enkephalin knock-out mice (Brady et al., 1999), or after MS (Ploj et al., 2003a). These negative results do not refute the hypothesis but indicate that changes in the $\mu$-opioid receptor transduction pathway (coupling to Gi-protein, ability of adenylyl cyclase to inhibit the cAMP pathway), which are not detected in autoradiography, could occur.

This study shows that MD affects the behavior and the activity of the enkephalinergic system of the pups subsequently, when adults. $\mathrm{D}$ rats were hypersensitive to the reinforcing effects of morphine and developed morphine dependence consistently with a basal hypoactivity of the enkephalinergic system. The opioidergic system plays a fundamental role in brain reinforcement processes, and several addictive compounds were shown to interact with it. Indeed, strong relationships between sucrose and the opioidergic system were demonstrated. Endogenous opioids, especially in the N.Acc., are implicated in the ingestion of palatable solutions and play a major role in the hedonic evaluation of food and fluid. High saccharin preference is correlated with a higher intake of intravenous morphine (for review, see Kelley et al., 2002). We speculated that as for morphine, D rats could be more sensitive to sucrose than ND rats. When rats had access to a low concentration of sucrose for a long period ( $90 \mathrm{~d})$, D rats progressively developed a slight but significant sucrose preference from 
50 to $70 \%$, indicating that $\mathrm{D}$ rats were more sensitive to the reinforcing effect of sucrose than ND rats. However, the strong increase in morphine chronic intake clearly showed a specificity for opiate vulnerability, to an extent that is not reached for sucrose consumption.

Together, these results suggest that MD in pups likely represents a risk factor for morphine responsiveness and dependence for morphine in adult rats. This model of vulnerability to addictive compounds could be helpful to understand the neuronal dysfunctions that occur in addiction and to develop new potential therapeutic and preventive approaches aiming at decreasing this vulnerability after the postnatal period.

\section{References}

American Psychiatric Association (2000) Diagnostic and statistical manual of mental disorders, Ed 4, revised. Washington, DC: American Psychiatric Association.

Anisman H, Zaharia MD, Meaney MJ, Meralis Z (1998) Do early-life events permanently alter behavioral and hormonal responses to stressors. Int J Dev Neurosci 16:149-164.

Brady LS, Herkenham M, Rothman RB, Partilla JS, Kônig M, Zimmer AM, Zimmer A (1999) Region-specific up-regulation of opioid receptor binding in enkephalin knockout mice. Mol Brain Res 68:193-197.

Caboche J, Vernier P, Julien JF, Rogard M, Mallet J, Besson M-J (1991) Parallel decrease of glutamic acid decarboxylase and preproenkephalin mRNA in the rat striatum following chronic treatment with a dopaminergic D1 antagonist and D2 agonist. J Neurochem 56:428-435.

Caldji C, Francis D, Sharma S, Plotsky PM, Meaney MJ (2000) The effects of early rearing environment on the development of $\mathrm{GABA}_{\mathrm{A}}$ and benzodiazepine receptor levels and novelty-induced fearfulness in the rat. Neuropsychopharmacology 22:219-229.

Canetti L, Bachar E, Galili-Weisstub E, De-Nour AK, Shalev AY (1997) Parental bonding and mental health in adolescence. Adolescence 32:381-394.

Carden S, Hofer M (1990) Socially mediated reduction of isolation distress in rat pups is blocked by naltrexone but not by RO15-1788. Behav Neurosci 104:457-464.

Cupo A, Jarry TH (1985) Detection of methionine-enkephalin at the $10^{-16}$ mole level. J Neuroimmunol 8:57-67.

Daugé V (2002) Impact neurobiologique de la séparation mère/nouveau-né chez le rongeur. Med Sci (Paris) 19:607-611.

Daugé V, Attoub S, Cupo A, Roques BP (1999) Peripheral stimulation of CCK-B receptors by BC264 induces a hyperexploration, dependent on the $\partial$ opioid system in the nucleus accumbens of rats. Neuropharmacology 38:999-1007.

de Kloet ER, Rots NY, Cools R (1996) Brain-corticosteroid hormone dialogue: slow and persistent. Cell Mol Neurobiol 6:345-356.

Deroche-Gamonet V, Belin D, Piazza PV (2004) Evidence for addiction-like behavior in the rats. Science 305:1014-1017.

Francis DD, Caldji C, Champagne FN, Plotsky PM, Meaney MJ (1999) The role of corticotropin-releasing factor-norepinephrine systems in mediating the effects of early experience on the development of behavioral and endocrine responses to stress. Biol Psychiatry 46:1153-1166.

Gerfen CR, McGinty JF, Young III WS (1991) Dopamine differentially regulates dynorphin, substance $\mathrm{P}$, and enkephalin expression in striatal neurons: in situ hybridization histochemical analysis. J Neurosci 11:1016-1031.

Giros B, Jaber M, Jones SR, Wightman RM, Caron MG (1996) Hyperlocomotion and indifference to cocaine and amphetamine in mice lacking the dopamine transporter. Nature 379:606-612.

Hall FS, Wilkinson LS, Humby T, Robbins TW (1999) Maternal deprivation of neonatal rats produces enduring changes in dopamine function. Synapse 32:37-43.

Harris JC, Newman JD (1988) Combined opiate-adrenergic receptor blockade enhances squirrel monkey vocalization. Pharmacol Biochem Behav 31:223-226.

Holmes SJ, Robins LN (1987) The influence of childhood disciplinary experience on the development of alcoholism and depression. J Child Psychol Psychiatry 28:399-415.

Howells RD, Kilpatrick DL, Bhatt R, Monahan JJ, Poonian M, Udenfriend S (1984) Molecular cloning and sequence determination of rat preproen- kephalin cDNA: sensitive probe for studying transcriptional changes in rat tissues. Proc Natl Acad Sci USA 81:7651-7655.

Huot RL, Thrivikraman KV, Meaney MJ, Plotsky PM (2001) Development of adult ethanol preference and anxiety as a consequence of neonatal maternal separation in Long-Evans rats and reversal with antidepressant treatment. Psychopharmacology 158:366-373.

Kalinichev M, Easterling KW, Holtzman SG (2001) Early neonatal experience of Long-Evans rats results in long-lasting changes in morphine tolerance and dependence. Psychopharmacology 157:305-312.

Kalinichev M, Easterling KW, Holtzman SG (2002) Long-lasting changes in morphine-induced locomotor sensitization and tolerance in Long-Evans mother rats as a result of periodic postpartum separation from the litter: a novel model of increased vulnerability to drug abuse? Neuropsychopharmacology 28:317-328.

Kelley AE, Bakshi VP, Haber SN, Steininger TL, Will MJ, Zhang M (2002) Opioid modulation of taste hedonics within the ventral striatum. Physiol Behav 76:365-377.

Koob GF (1992) Drugs of abuse: anatomy, pharmacology and function of reward pathways. Trends Pharmacol Sci 13:177-184.

Kosten TA, Miserendino MJD, Kehoe P (2000) Enhanced acquisition of cocaine self-administration in adult rats with neonatal isolation experience. Brain Res 875:44-50.

Ladd CO, Owens MJ, Nemeroff CB (1996) Persistent changes in corticotropin-releasing factor neuronal systems induced by maternal deprivation. Endocrinology 137:1212-1218.

Ladurelle N, Keller G, Blommaert A, Roques BP, Daugé V (1997) The CCK-B agonist, BC264, increases dopamine in the nucleus accumbens and facilitates motivation and attention after intraperitoneal injection in rats. Eur J Neurosci 9:1804-1814.

Martin S, Manzanares J, Corchero J, Garcìa-Lecumberri C, Crespo JA, Fuentes JA, Ambrosio E (1999) Differential basal proenkephalin gene expression in dorsal striatum and nucleus accumbens, and vulnerability to morphine self-administration in Fischer 344 and Lewis rats. Brain Res 821:350-355.

Mathieu-Kia A, Besson M-J (1997) Repeated administration of cocaine, nicotine and ethanol: effects on preprodynorphin, preprotachykinin A and preproenkephalin mRNA expression in the dorsal and the ventral striatum of the rat. Mol Brain Res 54:141-151.

Matthews K, Robbins TW (2003) Early experience as a determinant of adult behavioral responses to reward; the effects of repeated maternal separation in the rat. Neurosci Biobehav Rev 27:45-55.

McCormick CM, Kehoe P, Kovacs S (1998) Corticosterone release in response to repeated, short episodes of neonatal isolation:evidence of sensitization. Int J Dev Neurosci 16:175-185.

McLachlan CD, Hay M, Coleman GJ (1994) The effects of exercise on the oral consumption of morphine and methadone in rats. Pharmacol Biochem Behav 48:563-568.

Meaney MJ, Aitken DH, Sharma S, Viau V, Sarrieau A (1989) Postnatal handled increases hippocampal type II, glucocorticoid receptors and enhances adrenocortical negative-feedback efficacy in the rat. Neuroendocrinology 51:597-604.

Meaney MJ, Brake W, Gratton A (2002) Environmental regulation of the development of mesolimbic dopamine system: a neurobiological mechanism for vulnerability to drug abuse? Psychoendocrinology 27:127-138.

Nylander I, Vlaskovska M, Terenius L (1995) Brain dynorphin and enkephalin systems in Fischer and Lewis rats: effects of morphine tolerance and withdrawal. Brain Res 683:25-35.

Paul IA, English JA, Halaris A (2000) Sucrose and quinine intake by maternally-deprived and control rhesus monkeys. Behav Brain Res 112:127-134.

Paxinos G, Watson C (1986) The rat brain in stereotaxic coordinates. New York: Academic.

Ploj K, Roman E, Nylander I (2003a) Long-term effects of maternal separation on ethanol intake and brain opioid and dopamine receptors in male Wistar rats. Neuroscience 121:787-799.

Ploj K, Roman E, Nylander I (2003b) Long-term effects of short and long periods of maternal separation on brain opioid peptide levels in male Wistar rats. Neuropeptides 37:149-156.

Pryce CR, Feldon J (2003) Long-term neurobehavioral impact of the postnatal environment in rats: manipulations, effects and mediating mechanisms. Neurosci Biobehav Rev 27:57-71.

Pryce CR, Bettschen D, Bahr NI, Feldon J (2001) Comparison of the effects 
of infant handling, isolation, and non-handling on acoustic startle, prepulse inhibition, locomotion, and HPA activity in the adult rat. Behav Neurosci 115:71-83.

Reisine T, Pasternak G (1996) Opioid analgesics and antagonists. In: Goodman and Gilman's the pharmacological basis of therapeutics, Ed 9 (Hardman JG, Gilman AG, Limbird LE, eds), pp 521-555. New York: McGraw-Hill.

Sellings L, Clarke P (2003) Segregation of amphetamine reward and locomotor stimulation between nucleus accumbens medial shell and core. J Neurosci 23:6295-6303.

Shippenberg TS, Bals-Kubik R, Herz A (1993) Examination of the neurochemical substrates mediating the motivational effects of opioids: role of the mesolimbic dopamine system and D-1 vs. D-2 dopamine receptors. J Pharmacol Exp Ther 265:53-59.

Tzschentke TM (1998) Measuring reward with the conditioned place preference paradigm: a comprehensive review of drug effects, recent progress and new issues. Prog Neurobiol 56:613-672.
Vaccarino AL, Olson GA, Olson RD, Kastin AJ (1999) Endogenous opiates; 1998. Peptides 20:1527-1574.

Valverde O, Smadja C, Roques BP, Maldonado R (1997) The attenuation of morphine-conditioned place preference following chronic mild stress is reversed by a CCK-B receptor antagonist. Psychopharmacology 131:79-85.

Vazquez DM, Eskandari R, Zimmer CA, Levine S, Lòpez J (2002) Brain 5-HT receptor system in the stressed infant rat:implications for vulnerability to substance abuse. Psychoneuroendocrinology 27:245-272.

Wang H, Pélaprat D, Roques BP, Vanhove A, Chi ZQ, Rostène W (1991) $\left[{ }^{3} \mathrm{H}\right]$ Ohmefentanyl preferentially binds to $\mu$-opioid receptors but also labels sigma-sites in rat brain sections. Eur J Pharmacol 193:341-350.

Wise RA (1989) Opiate reward: sites and substrates. Neurosci Biobehav Rev 13:129-133.

Wolffgramm J, Heyne A (1995) From controlled drug intake to loss of control: the irreversible development of drug addiction in the rat. Behav Brain Res 70:77-94. 